\title{
Editorial
}

HORMONE

RESEARCH IN

Horm Res Paediatr 2014;81:361-362

DOI: $10.1159 / 000360700$

Published online: May 15, 2014

PADIATRICS

\section{Keep an Eye on lodine and the Thyroid and Save the Brain}

\author{
Peter Laurberg ${ }^{a, b}$ Stine Linding Andersen ${ }^{a, b}$ \\ ${ }^{a}$ Department of Endocrinology, Aalborg University Hospital, and ${ }^{b}$ Department of Clinical Medicine, Aalborg \\ University, Aalborg, Denmark
}

Thyroid hormones are indispensable developmental factors and a lack of adequate amounts of thyroid hormone during brain development may lead to irreversible brain damage [1]. Thus, it is vital that neonates diagnosed with hypothyroidism are treated fast and adequately to become euthyroid. In this issue of Hormone Research in Paediatrics, Kurtoğlu and colleagues from Kayseri, Turkey, report an interesting study where an iodine supplement was added to the obligatory levothyroxine replacement therapy of neonates diagnosed by screening to suffer from hypothyroidism [2].

A lack of thyroid hormone for proper brain development may have several main causes: (1) maternal thyroid insufficiency, because the thyroid hormones involved in steering the development in early pregnancy are entirely of maternal origin, and those involved in late pregnancy are partly of maternal (and partly of fetal) origin. The typical cause is autoimmune impairment of the thyroid in the mother, and it is much discussed if all pregnant women should be screened in early pregnancy for thyroid dysfunction [3]. (2) Fetal/neonatal/infant thyroid insufficiency is most often caused by developmental defects such as thyroid aplasia/hypoplasia/ectopia or abnormalities in processes involved in thyroid hormone production [4]. Screening for neonatal hypothyroidism is now part of public healthcare in many countries, but still only a minority of the world's newborns are screened [4]. (3) Insufficient thyroid hormone production in both the mother and the fetus/infant is typically caused by an insufficient

\section{KARGER}

E-Mail karger@karger.com

www.karger.com/hrp iodine content of the mother's diet. Iodine readily passes the placenta [5], and the mother's dietary iodine intake should cover the needs of both the maternal and the fetal thyroid hormone production. Compared with the nonpregnant state, the thyroid hormone production is up to $50 \%$ higher from early pregnancy due to a high degradation rate of $\mathrm{T}_{4}$ in the placenta/uterus unit and various other mechanisms [3]. Thus, iodine requirements are substantially increased in pregnancy [1]. During breastfeeding, around $40 \%$ of iodine in the mother's diet are transferred to the infant via breast milk $[6,7]$, and the mother's iodine intake should be relatively high to cover both her own needs and the iodine transfer via breast milk [1]. Smoking and other sources of thiocyanate diminish iodine transport into breast milk [8], and mothers who smoke or who are exposed to other inhibitors of the mammary gland iodine transport should have an even higher iodine intake.

A few months' delay in the diagnosis and therapy of congenital hypothyroidsm involves a high risk of some degree of permanent intellectual impairment of the child. As a consequence, a neonatal screening program for hypothyroidism was initiated in Turkey in 2006 [2]. Moreover, considerable parts of the Turkish population had previously been affected by iodine insufficiency, and a program of salt iodisation was introduced in the late 1990s [9].

Even if salt iodisation has in general increased iodine intake in the Turkish population [9], areas of low iodine
(C) 2014 S. Karger AG, Basel

1663-2818/14/0816-0361\$39.50/0
Peter Laurberg

Department of Medical Endocrinology

Aalborg University Hospital Science and Innovation Centre

Søndre Skovvej 15, Room 103, DK-9000 Aalborg (Denmark)

E-Mail peter.laurberg@ rn.dk 
intake are still to be found [10]. Kurtoğlu et al. [2] hypothesised that some of the neonates diagnosed with hypothyroidism by screening might have developed it because of low maternal iodine intake, and they performed a randomised study comparing therapy of hypothyroid neonates with levothyroxine alone versus levothyroxine plus iodine. The neonates included had high serum TSH, low $\mathrm{fT}_{4}$ and a spot urine iodine concentration $<100 \mu \mathrm{g} / \mathrm{l}$. Many details on the selection for the study are lacking, but apparently neonates with thyroid aplasia/hypoplasia/ectopia were excluded, because a normal or enlarged thyroid gland evaluated by ultrasonography was present in all the children, and they all had high serum thyroglobulin levels at inclusion. The children were studied before therapy and again after 1 and 3 months. No differences between the treatment groups were observed in the rates of serum TSH and $\mathrm{fT}_{4}$ normalisation, or in thyroid size and serum thyroglobulin.

The results of the study illustrate the effectiveness of the current standard therapy of neonatal hypothyroidism with levothyroxine. On the other hand, iodine supplements to the neonates had no effect.

Are the results of this study an indication that adequate iodine intake during pregnancy and lactation is of little importance for the thyroid function of the offspring? This is certainly not a conclusion to be drawn from the study.

Even if Kurtoğlu et al. [2] are to be congratulated for their prospective randomised study, there are some limitations to the study as was also pointed out by the authors.
Apparently, the study was not blinded to the mothers and judging by the measured iodine concentrations in breast milk and infant urine, the mothers in the levothyroxine only group tended to increase their iodine intake to compensate the risk they may have feared to their children. An important detail to consider when discussing iodine intake and levothyroxine therapy is that iodine constitutes $65 \%$ of levothyroxine by weight, and levothyroxine replacement therapy is also to some degree an iodine supplement.

Another limitation is the method used by Kurtoğlu et al. [2] to diagnose iodine deficiency as the cause for hypothyroidism in the neonates (a single spot urine iodine concentration $<100 \mu \mathrm{g} / \mathrm{l}$ ). Urinary iodine concentrations show large intraindividual variation, and in general iodine deficiency in an individual cannot be diagnosed from a single spot urine concentration [11]. Even if the neonates had low iodine intake, iodine deficiency would normally have to be much more severe than in this study to result in the high serum TSH levels recorded in these neonates [12], and if iodine deficiency was the only cause of the impaired neonatal thyroid function, the condition would be curable with simple iodine intake normalisation alone.

In conclusion, brain development is critically dependent on thyroid hormones and considerable effort should be devoted to keep pregnant women and their children euthyroid. This is done by adequate iodine nutrition and by early detection and therapy of thyroid function abnormalities in the mother and her fetus/child.

\section{References}

1 WHO, UNICEF, ICCIDD: Assessment of Iodine Deficiency Disorders and Monitoring Their Elimination. A Guide for Programme Managers. Geneva, World Health Organisation, 2007, pp 1-99.

\2 Kurtoğlu S, Köroğlu Ş, Baştuğ O, Daar G, Yıkılmaz A, Elmalı F: The comparison of thyroxine versus thyroxine plus oral iodine in the treatment of congenital hypothyroidism due to iodine deficiency. Horm Res Paediatr DOI: $10.1159 / 000358878$.

3 Laurberg P, Andersen SL, Pedersen IB, Andersen S, Carle A: Screening for overt thyroid disease in early pregnancy may be preferable to searching for small aberrations in thyroid function tests. Clin Endocrinol (Oxf) 2013;79: 297-304.

4 Rastogi MV, LaFranchi SH: Congenital hypothyroidism. Orphanet J Rare Dis 2010; 5:17.
5 Andersen SL, Nohr SB, Wu CS, Olsen J, Pedersen KM, Laurberg P: Thyroglobulin in smoking mothers and their newborns at delivery suggests autoregulation of placental iodide transport overcoming thiocyanate inhibition. Eur J Endocrinol 2013;168:723-731.

6 Andersen SL, Møller M, Laurberg P: Iodine concentrations in milk and in urine during breastfeeding are differently affected by maternal fluid intake. Thyroid 2014;24:764-772.

7 Laurberg P, Andersen SL: Nutrition: breast milk - a gateway to iodine-dependent brain development. Nat Rev Endocrinol 2014;10: 134-135.

8 Laurberg P, Nohr SB, Pedersen KM, Fuglsang $\mathrm{E}$ : Iodine nutrition in breast-fed infants is impaired by maternal smoking. J Clin Endocrinol Metab 2004;89:181-187.

9 Erdoğan MF, Demir O, Emral R, Kamel AN, Erdoğan G: More than a decade of iodine pro- phylaxis is needed to eradicate goiter among school age children in a moderately iodinedeficient region. Thyroid 2009;19:265-268.

10 Bayram F, Beyazyildiz A, Gökçe C, Budak N, Erdoğan N, Kurtoğlu S, Kula M, Unluhizarci $\mathrm{K}$, Keleştimur F: The prevalence of iodine deficiency, serum thyroglobulin, anti-thyroglobulin and thyroid peroxidase antibody levels in the urban areas of Kayseri, Central Anatolia. Exp Clin Endocrinol Diabetes 2009;117:64-68.

-11 Andersen S, Karmisholt J, Pedersen KM, Laurberg P: Reliability of studies of iodine intake and recommendations for number of samples in groups and in individuals. $\mathrm{Br} \mathrm{J}$ Nutr 2008;99:813-818.

12 Nohr SB, Laurberg P: Opposite variations in maternal and neonatal thyroid function induced by iodine supplementation during pregnancy. J Clin Endocrinol Metab 2000;85: 623-627. 